\title{
The Expression of Caspase-3 and Survivin Related with Induction Chemotherapy in Childhood Acute Lymphoblastic Leukemia
}

\author{
Ingga Gebyarani ${ }^{1}$, Susanto Nugroho ${ }^{2}$, Edi Widjajanto ${ }^{3}$ \\ ${ }^{1}$ Senior Paediatric Resident, Biomedical Science Master Study Program, Faculty of Medicine University of \\ Brawijaya/Saiful Anwar Hospital, Malang, Indonesia \\ ${ }^{2}$ Head of Hematology and Oncology Division, Department of Paediatrics, Faculty of Medicine University of \\ Brawijaya/Saiful Anwar Hospital, Malang, Indonesia. \\ ${ }^{3}$ Professor, Department of Clinical Pathology, Faculty of Medicine University of Brawijaya/Saiful Anwar \\ Hospital, Malang, Indonesia
}

\begin{abstract}
Recent therapeutic strategies in acute lymphoblastic leukemia (ALL) have been developed for the prognostic and hematological response or remission. Most chemotherapeutic agents induce tumor cell death by apoptosis. Therefore, regulation of the apoptotic and anti-apoptotic proteins influence treatment outcome. The mechanisms of caspase-3 and survivin have not been well investigated in childhood ALL. The aim of this study was to compare the active caspase-3 and survivin before and after receiving induction chemotherapy in ALL and to determine caspase-3/survivin ratio. The peripheral blood mononuclear cell was collected from ALL children before treatment and 6 weeks after starting induction therapy. Caspase-3 and survivin was measured by flow cytometry using monoclonal antibodies. Data were analysed by Kruskal-Wallis and Mann Whitney for comparison between groups, Spearman's test and linier regression to find out correlation between variables with significant value $p<0.05$. A total of 36 children were evaluated. The intensity of caspase-3 expression and ratio of caspase-3/survivin were significantly elevated in the after treatment group compared with the levels prior to chemotherapy, but no significant difference of caspase-3 compared with its expression in control group. Survivin was significantly decreased after induction chemotherapy compared to that at diagnosis $(p=0.000)$. There was strong inverse correlation between survivin and caspase-3/survivin ratio before chemotherapy $(r=-0.769, p=0.003)$, but no correlation between caspase-3 and survivin within group. It was concluded that the higher survivin expression, the lower caspase-3/survivin ratio. Caspase-3 expression and caspase-3/survivin ratio were increased, whereas survivin expression was decreased after induction chemotherapy.
\end{abstract}

Keywords: caspase-3, survivin, acute lymphoblastic leukemia.

Accepted Date: 06 July 2013

\section{INTRODUCTION}

Acute lymphoblastic leukemia (ALL) is the most common childhood cancer [1, 2]. ALL accounts for about $80 \%$ of childhood leukemia with peak prevalence between the ages of 2 and 5 years [3], and ranging from 9-10 cases/100,000 persons/year in childhood [4].

A major problem in hematological malignancies is primarily concerned with resistance to chemotherapy or failure to achieve complete remission after induction therapy and related to defects in apoptotic pathways [5]. Elimination of cancer cells by cytotoxic therapies, such as chemotherapy aimed at inducing cell death in the target cell. The expression level of effector caspases in tumor cells is a major determinant in the effectiveness of anticancer agents. Expression levels of certain caspases in tumor cells may have an impact on their activity, since a lower protein concentration may lead to a decrease in apoptosis [6]. All apoptotic pathways, either extrinsic (death receptor) or intrinsic (mitochondria) result in the activation of effector caspases 3 dan 7 [7]. Besides being used as a target therapeutic modulation, caspase- 3 is also clinically useful for determining the prognosis of leukemia patients. Caspase-3 can be used to predict a patient's response or complete remission after induction chemotherapy in acute leukemia [8]. Currently, strategies modulating the activity of genes and proteins in the apoptotic pathway in the treatment of hematologic malignancies continue to be developed [9].

A group of apoptosis inhibitor molecules called inhibitor of apoptosis proteins (IAP) interact with these downstream caspases blocking their activation. One member of the IAP family is survivin (BIRC5), a bifunctional protein that suppresses apoptosis and regulates cell division [7,10]. Survivin can inhibit caspase-3. The prognostic value of survivin in hemopoietic neoplasias has not been as widely studied as in solid tumors. Although the data are limited, the prognostic value of survivin has been studied in some hemopoietic neoplasias such as high grade lymphomas and leukemias [11]. Role of survivin is considered very important in the 
proliferation and oncogenesis in cell growth regulation. However, survivin was detected significantly in patients with cancer, such as lung cancer, genito-urinary cancer, stomach cancer, colon cancer, liver cancer, pancreatic cancer and soft tissue cancers. An increase in the expression of survivin in various malignancies correlates with the incidence of relapse and treatment failure and poor patient survival of acute lymphoblastic leukemia [12].

Previous studies were rarely performed in childhood hematologic malignancies. Most research of caspase were conducted in acute myeloblastic leukemia patients, whereas survivin is still limited in solid tumor research [12]. The results obtained earlier are still controversial. The ratio between pro-apoptotic and antiapoptotic proteins is believed to be a prognostic indicator in ALL patients compared to measurements using only one promoter alone [13]. Role of caspase-3 as a pro-apoptotic protein, survivin as an anti-apoptotic protein and the caspase-3/ survivin ratio remains unclear and has not been well investigated in acute leukemia. Therefore, the aim of this study was to determine the active caspase- 3 and survivin before and after receiving induction chemotherapy in pediatric ALL.

\section{METHODS}

This study was a cross sectional research and carried out on 36 children categorized into: Group 1 (before chemotherapy):12 patients with de novo ALL groups 2(after chemotherapy): 12 patients after receiving induction chemotherapy for 6 weeks; and group 3(controls): 12 non leukemic patients. ALL patients were categorized as standard risk or high risk categories. The standard risk group consists of children aged from 1-10 years with an initial leucocytes count of less than $50 \times 10^{9} / \mathrm{l}$, all other patients were considered to have high risk ALL. The study was conducted at the Paediatrics Department of Saiful Anwar Hospital and Biomedical laboratory of University of Brawijaya Malang from March to June 2013. This study has been approved by the committee of ethical clearance. Samples that meet the inclusion and exclusion criteria were obtained with the informed consent of patient's parents.

Inclusion criteria for cases were children aged 1-14 years diagnosed with ALL based on history taking, physical examination, bone marrow aspiration and positive immunophenotyping for at least two B-cell associated markers (CD19 and CD20) or T-cell associated markers (CD3,CD5,CD7) by flow cytometry.

Exclusion criteria for cases were patients with autoimmune disease or dropped out from induction chemotherapy. ALL patients received intratechal methotrexates, intravenous vincristine, daunorubicin, Lasparaginase and oral prednisone as induction chemotherapy of Indonesian protocol for 42 days or 6 weeks. Controls were non leukemic patients based on history, physical examination and peripheral blood smear.

Patients receiving steroids, having other malignancies or complications, such as shock, seizure, decrease of consciousness were excluded from controls.

Peripheral blood mononuclear cells (PBMC) were isolated from EDTA blood by Ficoll-Hypaque density gradient centrifugation. Intracellular staining of protein was performed according to the manufacturer's instructions. Phycoerythine (PE) labeled anti-survivin monoclonal antibodies were provided by R\&D system inc.(catalog \#:IC6472P) and fluorescein isothyocyanate (FITC) labeled anti-caspase-3 monoclonal antibodies were obtained from Santacruz (catalog \#:sc7272FITC). Briefly, cells were incubated in the dark at $18-24^{\circ} \mathrm{C}$ for 15 minutes. Cells were added by cell staining buffer in each sample and centrifuged at $1500 \mathrm{rpm}$ for 5 minutes.

Cells then were fixed by fixation buffer in the dark at $18-24^{\circ} \mathrm{C}$ for 20 minutes and centrifuged at 1500 rpm for 5 minutes. Cell pellet was washed with permeabilization buffer. They were then incubated with cocktail of FITC anti-caspase- 3 and PE anti-survivin in the dark at room temperature for 30 minutes. All the labeled cells were resuspended in $0,5 \mathrm{~mL}$ cell staining buffer and analyzed by flow citometry using the FACSCalibur instrument (Becton Dickinson) and the Cell Quest software package (Becton Dickinson).

In this study, data analysis techniques will be calculated in four stages, respectively: (1) Normality test of data sample with Shapiro-Wilk test, (2) When the normality test showed abnormal distribution of data, we used Spearman's test to find out correlation between variables,(3)Linier regression, (4) Kruskal-Wallis and Mann-Whitney's tests were done for comparison between groups. Statistical analysis of data was performed with the software of SPSS for Windows 16.0. The data are presented as means \pm standard deviations.

\section{Results}

The study included 36 patients who had inclusion and exclusion criteria. All subjects ranged in age between $1-13$ years with a mean of $6.58 \pm 3.79$ years. Boys are more than girls. ALL cases had an initial WBC count ranging between $1880-143000$ cells/cmm. Statistical analysis showed no significant differences between sex, age, hemoglobin level and leucocytes count in all groups. After receiving induction chemotherapy, $11(91,67 \%)$ patients achieved complete remission and had lymphoblast count less than $1 \%$ in their bone marrow aspirations, whereas $1(8,3 \%)$ was in partial remission who had lymphoblast count $12 \%$ in his bone marrow. According to FAB classification, $7(53,84 \%)$ showed L1 morphology and $5(41,67 \%)$ showed L2 morphology. There is no L3 morphology in our samples. Baseline characteristics and hematological findings of the patients included in this study were demonstrated (Table 1). 
Table 1 Baseline characteristics and hematological findings of the patients

\begin{tabular}{|c|c|c|c|c|c|}
\hline Characteristics & $\begin{array}{l}\text { Before } \\
\text { chemotherapy } \\
(\mathrm{n}=12), \mathrm{n}(\%)\end{array}$ & $\begin{array}{l}\text { After } \\
\text { chemotherapy } \\
(\mathrm{n}=12), \mathrm{n}(\%)\end{array}$ & $\begin{array}{l}\text { Control } \\
(\mathrm{n}=12), \mathrm{n}(\%)\end{array}$ & $\begin{array}{l}\text { Total } \\
(n=36)\end{array}$ & Pvalue \\
\hline Sex & & & & & 0.892 \\
\hline Male & $10(27.8 \%)$ & $6(16.7 \%)$ & $7(19.4 \%)$ & $23(63.9 \%)$ & \\
\hline Female & $2(5.6 \%)$ & $6(16.7 \%)$ & $5(13.9 \%)$ & $13(36.1 \%)$ & \\
\hline Age & & & & & 0.836 \\
\hline $1-10$ years & $9(25.0 \%)$ & $10(27.8 \%)$ & $7(19.4 \%)$ & $26(72.2 \%)$ & \\
\hline$>10-14$ & $3(8.3 \%)$ & $2(5.6 \%)$ & $5(13.9 \%)$ & $10(27.8 \%)$ & \\
\hline \multicolumn{6}{|l|}{ years } \\
\hline Leucocytes & & & & & 0.539 \\
\hline$<50000$ & $7(19.4 \%)$ & $12(33.3 \%)$ & $12(33.3 \%)$ & $31(86.1 \%)$ & \\
\hline$\geq 50000$ & $5(13.9 \%)$ & $0(0 \%)$ & $0(0 \%)$ & $5(13.9 \%)$ & \\
\hline $\mathrm{Hb}$ & & & & & 0.377 \\
\hline$<10$ & $10(27.8 \%)$ & $2(5.6 \%)$ & $2(5.6 \%)$ & $14(38.9 \%)$ & \\
\hline$\geq 10$ & $2(5.6 \%)$ & $10(27.8 \%)$ & $10(27.8 \%)$ & $22(61.1 \%)$ & \\
\hline Platelets & & & & & 0.012 \\
\hline$<150000$ & $11(30.6 \%)$ & $0(0 \%)$ & $3(8.3 \%)$ & $14(38.9 \%)$ & \\
\hline$\geq 150000$ & $1(2.8 \%)$ & $12(33.3 \%)$ & $9(25.0 \%)$ & $22(61.1 \%)$ & \\
\hline
\end{tabular}

The parameter of apoptosis is increase in caspase-3 expression and decrease in survivin expression after receiving induction chemotherapy. Caspase-3 expression intensity after induction treatment was significantly elevated with a mean intensity of $66.86 \pm 2.54 \%$ when compared with the level before chemotherapy. The caspase-3 level after chemotherapy was also higher than control group, yet statistically non significant. When we compared the expression of survivin before and after induction chemotherapy between cases, we found that the level of survivin was $67.48 \pm 8.07$ before induction phase and $58.15 \pm 3.17$ after induction. This difference was statistically significant with $\mathrm{p}$ value $=0.000$. After induction chemotherapy, survivin level was decreased, but not significant compared with the level in control group (Figure 1).

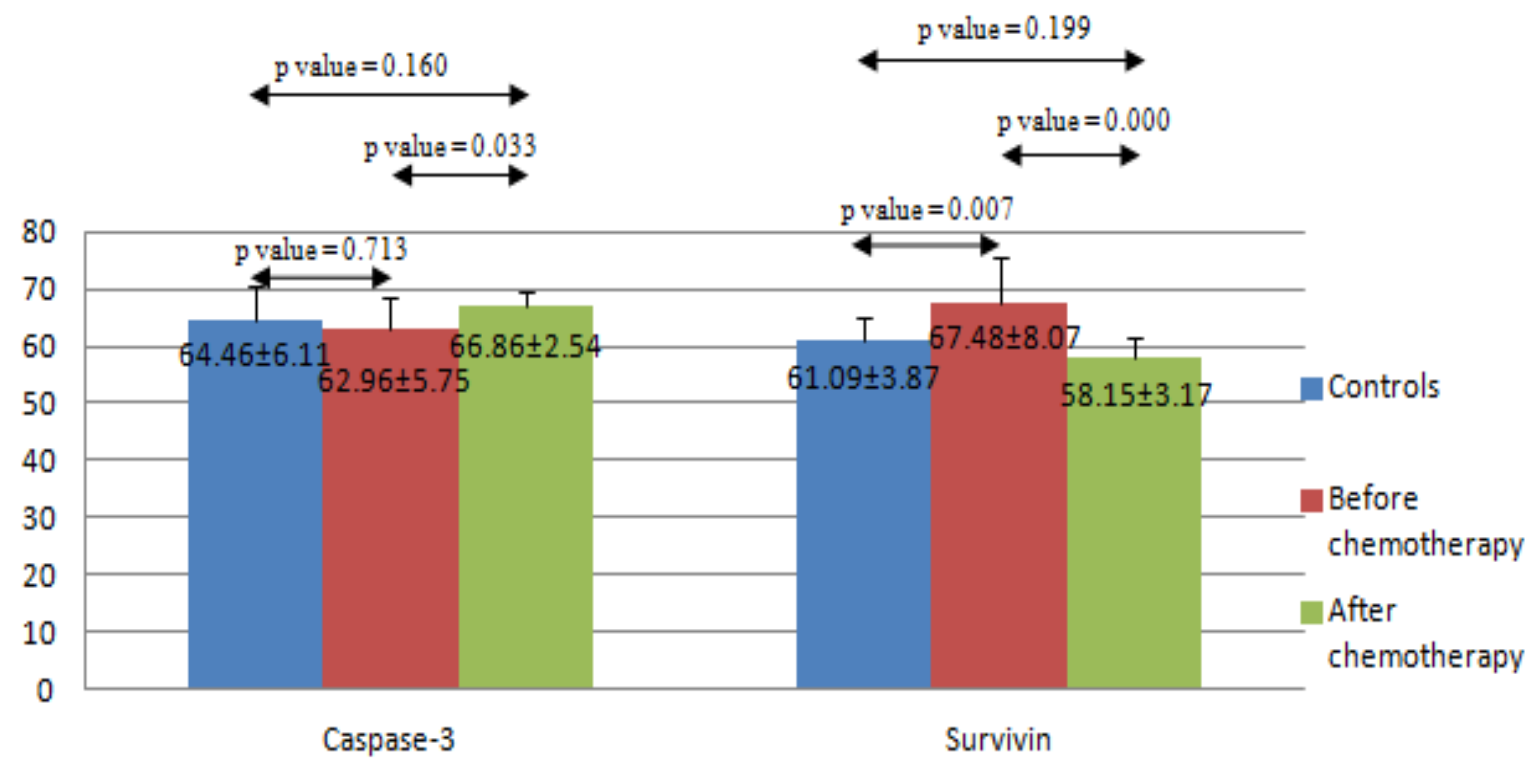

Figure 1. Result of Mann Whitney test in comparison of caspase-3 and survivin expression intensity $(\%)$ between groups 


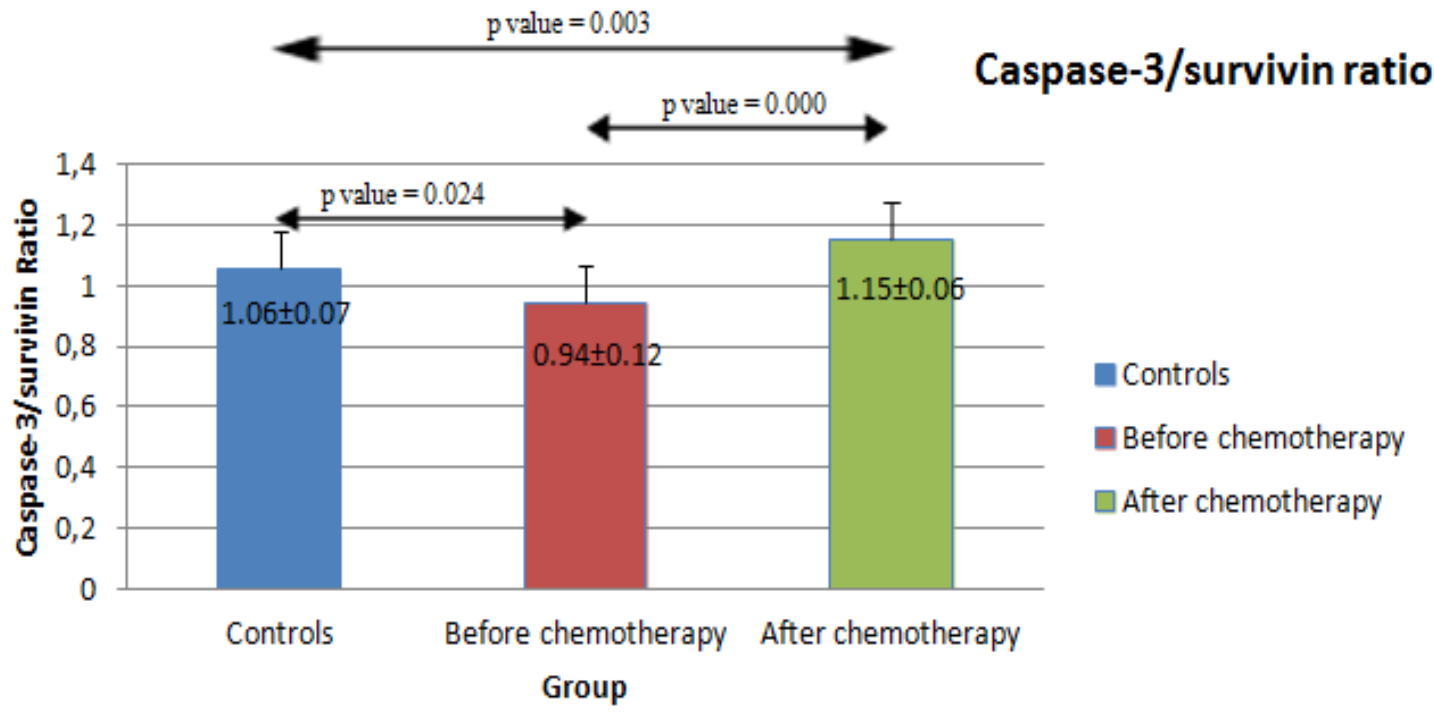

Figure 2. Result of Mann Whitney test in caspase-3/survivin ratio between groups

Figure 2 showed caspase-3/survivin ratio were significant in all groups. A highly significant elevation $(P<0.0001)$ was found in caspase-3/survivin ratio after receiving induction chemotherapy compared with the ratio at diagnosis. Pro-apoptotic/anti-apoptotic ratio has been found to be significant parameter in acute lymphoblastic leukemia patients.

Table 2 Result of correlation analysis between caspase-3, survivin and caspase-3/survivin ratio

\begin{tabular}{|l|c|c|c|c|c|c|}
\hline \multirow{2}{*}{ Group } & \multicolumn{2}{|c|}{$\begin{array}{c}\text { Correlation between } \\
\text { caspase-3 and survivin }\end{array}$} & \multicolumn{2}{|c|}{$\begin{array}{c}\text { Correlation between } \\
\text { caspase-3 and } \\
\text { caspase-3/survivin ratio }\end{array}$} & \multicolumn{2}{|c|}{$\begin{array}{c}\text { Correlation between } \\
\text { survivin and } \\
\text { caspase-3/survivin ratio }\end{array}$} \\
\cline { 2 - 7 } & $\begin{array}{c}\text { Coeficient } \\
\text { correlation } \\
\text { (r) }\end{array}$ & P value & $\begin{array}{c}\text { Coeficient } \\
\text { correlation } \\
\text { (r) }\end{array}$ & P value & $\begin{array}{c}\text { Coeficient } \\
\text { correlation } \\
\text { (r) }\end{array}$ & P value \\
\hline Control & 0.437 & 0.155 & 0.531 & 0.076 & -0.529 & 0.077 \\
\hline $\begin{array}{l}\text { Before } \\
\text { chemotherapy }\end{array}$ & 0.350 & 0.265 & 0.245 & 0.443 & -0.769 & 0.003 \\
\hline $\begin{array}{l}\text { After } \\
\text { chemotherapy }\end{array}$ & 0.538 & 0.071 & 0.455 & 0.138 & -0.322 & 0.308 \\
\hline
\end{tabular}

Spearman's correlation analysis showed there were one strong significant inverse correlation between survivin and caspase-3/survivin ratio with coeficient correlation $(r)=-0.769$ and $p$ value $=0.003$, whereas other correlations were not significant. In linier regression analysis, our study revealed that $\mathrm{R}$ square 0.479 and $\mathrm{p}$ value 0.008 .

\section{Discussion}

In this study, peripheral blood specimens from 36 patients were analyzed and divided into groups of control, before and after induction chemotherapy. ALL patients were children aged range of 1 to 13 years with the peak age was 4 years. Boys is more dominant than girls with a ratio of 1.7:1. This result is consistent with the proportion of the age and sex of patients with ALL in Central Java, where the study involved 196 children which are 79\% of children aged 1-10 years old and predominantly male with a ratio of 1.4:1 and the peak incidence was 3.05 years [14].

According to the National Cancer Institute (NCI) or the Rome criteria, ALL stratification are divided into age 1-10 years and leucocytes count of less than $50.000 / \mu \mathrm{L}$ as standard risk, and age $\geq 10$ years and / or a leucocytes count $\geq 50.000 / \mu \mathrm{L}$ as high-risk ALL. Leucocytes count and age at the time of initial diagnosis is an important predictive factor for treatment outcomes [15]. This study shows 5 (13.9\%) patients with initial leukocyte counts $\geq 50.000 / \mu \mathrm{L}$, although statistically not significant. After induction chemotherapy, complete remission (blast cells in the bone marrow is less than 5\%) was found in 11 (91.67\%) samples and only 1 child showed residual disease.

This study showed a high expression intensity of caspase-3 after induction chemotherapy compared with the expression before chemotherapy. Defects in apoptotic pathway associated with the resistance to 
chemotherapy drugs. Increase in pro-apoptotic protein indicates chemosensitivity after induction phase in ALL children. Several other clinical studies also supported the role of caspase-3 as a pro-apoptotic protein in acute leukemia. Increased activation of caspase-3 as an effector of apoptosis was found in 50 samples of peripheral blood collection ALL patients who received exposure to prednisolone, vincristine, L-asparaginase and daunorubicin, and showed inverse correlation to chemoresistance [16]. Previous research by western blot analysis showed that caspase-3 levels were high (> 0.37) and the most significant predictors for complete remission with $p$ value $=0.025$ [17]. Our results go in agreement with Meyer et al. [18], who studied caspase-3 using flow cytometry in AML patients, reported that the complete remission and a good prognosis correlated with activation of caspase-3.

Caspase-3 as an effector caspase performs the actual cell destruction and are proteolytically activated by the apical caspases (caspase- 8 , caspase-9) that initiate the caspase cascade through death receptor signaling complex via the extrinsic pathway and the intrinsic mitochondria-mediated pathway or by the granzyme B $[19,20]$. Cytotoxic therapies such as chemotherapy induced cell death depends on the target [21]. In our study, the expression of caspase- 3 did not differ significantly in the control group. This is due to the expression of caspase-3 was also identified in normal mammalian cells as the primary effector caspase. Caspase-3 is also involved in a number of nonapoptotic events including proliferation of forebrain cells, keratinocytes, and B cells, MHC II expression dendritic cell maturation, differentiation of neural stem cells, myoblast, osteoblasts, platelets, erytroblast and lens epithelial cells [22].

Another factors that can affect the outcome of caspase-3 in this study are the different time of sample measurement after receiving chemotherapy and low number of patients. The detection of apoptosis sometimes failed, due to the rapid removal of pro-apoptotic cells from circulation [23]. Other study obtained a significant correlation between increased activity of caspase-3 within 6 hours and 24 hours after chemotherapy [24]. Research in Egypt on 20 ALL patients aged 2-14 years also showed no significant difference of caspase-3 in controls, but the levels of caspase- 3 after the induction phase proved to be significantly higher than that before chemotherapy and caspase-3 is a predictor of the occurrence of remission [25]. Mutation of oncogene that can inhibit apoptosis may also affect the results of caspase-3 expression. There are two major ways that could downregulate cancer cell apoptosis: (1) somatic and non-somatic mutation which causes loss of pro-apoptotic expression molecule, and (2) overexpression of apoptosis inhibitory molecules. Somatic mutations of apoptosis related genes affect several proteins. Mutations in the caspase family are not infrequently found in malignancies, including leukemia. Other study mentioned somatic mutations of caspase- 3 was found in 45 patients with acute leukemia compared to controls. This suggests that the mutation causes a defect in the induction of apoptosis [26].

In this study, analysis of correlation between caspase-3 and survivin was not significant. According to various studies, survivin mechanism remains unclear. Studies suggest that survivin protein is binding directly with caspase-3 and caspase-7. Interaction with caspase-3, caspase-7, and caspase-9 by preventing their activation [27]. Survivin plays a role in inhibition of apoptosis and is associated with a decrease in apoptotic index in human cancer cells [28]. However, others revealed that survivin does not bind caspases. There was indirect association between survivin and caspase-3 by enhancing XIAP stability (XIAP-survivin complex) and inhibiting caspase activation, or direct binding to SMAC / DIABLO [7,29].

Based on the results of pro-apoptotic/anti-apoptotic protein ratio in this study, the parameter between survivin and caspase-3/survivin ratio showed a significant inverse correlation with a coefficient $R=-0.769(p=$ 0.003 ) before chemotherapy, while it is not statistically significant after induction chemotherapy. This means that the higher survivin, the lower caspase-3/survivin ratio at diagnosis. Other correlation between caspase- 3 and caspase-3/survivin is not significant in all groups. This may be caused by other pro-apoptotic and anti-apoptotic proteins activated after administration of chemotherapy drugs.

Survivin is expressed in a cell-cycle-dependent manner with the highest levels of expression in G2/M phase. Cellular location of survivin also relatively affects the ratio between survivin, downstream caspase and protein stabilizers. survivin $2 \mathrm{~B}$ was found in the cytoplasm, whereas the anti-apoptotic survivin ${ }^{8}$ Exon 3 located in the nucleus. The cytosolic survivin fraction is more dominant than the nucleus fraction [30]. High concentrations of survivin protein can block apoptosis pathway through inhibition in distal effector caspase-3 indirectly. Survivin interacts with pro-apoptotic proteins, SMAC molecule inhibits IAP, thus preventing the activation of caspase-3 [29]. As a consequence of increased survivin, the free active caspase-3 would not reach the threshold level (threshold level), so it does not trigger apoptosis. The combination of chemotherapy and the down-regulation of survivin by survivin antagonists (EZN-3042) can eradicate leukemia cells and lower in patients with ALL chemoresistance [31]. Chemotherapeutic drug doxorubicin, a DNA damaging agent, modulates the expression of survivin by activating a p53-survivin signaling pathway, inducing cell cycle arrest and apoptosis in childhood acute lymphoblastic leukemia [32].

Our result showed a high survivin expression in patients with ALL prior to chemotherapy than controls. This is concordant with a research by Troeger et al. [33], who found survivin overexpression in 66 patients 
with B-cell precursor ALL and high risk of early relapse. This study also obtains a lower survivin expression after the induction phase of chemotherapy than before chemotherapy $(\mathrm{p}=0.000)$. Results of different studies shown by Esh et al. [12], there was no significant difference between the expression of survivin at the beginning of diagnosis and after induction chemotherapy in 30 children ALL with flow cytometry method ( $p=0.688$ ). Yahya et al. [34], also found similar result in a highly significant elevation of protein survivin level in children with ALL compared to control group and this elevation decreased at remission and approached the control level. It has been shown that survivin expression is frequent in malignant tumors and is a new target for therapy.

Design of this study using cross-sectional methods because of time, cost, and number of sample limitations. This is the first preliminary study on caspase-3 and survivin expression in Indonesian ALL patients. Other studies focused on immunophenotyping and genetics. Our study is expected to be the basis for the development of ALL protocols with the target therapy on pro-apoptotic and anti-apoptotic proteins.

\section{Conclusions}

Caspase-3 expression and caspase-3/survivin ratio were increased, while survivin expression was decreased after induction chemotherapy. Survivin fulfills its dual role in apoptosis and mitosis that requires further cohort prospective study with a large number of samples using the gold standard of apoptosis to be a prognostic marker in pediatric ALL.

\section{References}

[1] Gaynon P.S. Childhood acute lymphoblastic leukemia and relaps. British J Haematol, 13, 2005, 579-87.

[2] Spector L.G., Ross J.A., Robison L.L. Epidemiology and etiology in childhood leukemias (New York: Cambridge University Press, 2006) 48-61.

[3] Pui C.H., Robinson L.L., Look A.T. Acute lymphoblastic leukemia. Lancet. 371, 2008,1030-43.

[4] Ribera J.M.and Oriol A. Acute lymphoblastic leukemia in adolescents and young adults. Hematol Oncol Clin North Am, 23(5), 2009, 1033- 42 .

[5] Ross D.D. Novel mechanisms of drug resistance in leukemia. Leukemia, 14, 2000, 467-473.

[6] MacKenzie S.H.and Clark A.C. Targeting cell death in tumors by activating caspases. Current cancer drug targets, 8, 2008,98-109.

[7] Altieri D.C. Survivin and IAP proteins in cell death mechanisms. Biochem J. 430, 2010, 199-205.

[8] Schimmer A.D., Pedersen I.M., Kitada S., et al. Functional blocks in caspase activation pathways are common in leukemia and predict patient response to induction chemotherapy. Cancer Res. 63, 2003, 1242-48.

[9] Fulda S. And Debatin K.M. Extrinsic versus intrinsic apoptosis pathways in anticancer chemotherapy. Oncogene, 25, 2006, 4798811.

[10] Dohi T., Okada K., Xia F., et al. An IAP-IAP complex inhibits apoptosis. J Biol Chem, 279 (33), 2004, 34087-34090

[11] Carter B.Z., Wang R.Y., Schober W.D., Milella M., Andreeff M. Targeting survivin expression induces cell proliferasion defect and subsequent celldeath involving mitochondrial pathway in myeloid leukemic cell. Cell cycle, 2 (5), 2003, 488-493.

[12] Esh A.M., Atfy M., Azizi N.A., El Naggar M.M.,Khalil E.E., Sherief L. Prognostic Significance of survivin in Pediatric Acute Lymphoblastic Leukemia.Indian J Hematol Blood Transfusion, 27(1), 2011, 18-25.

[13] Prokop A., Wieder T., Sturm I., Mann F.E., Seeger K., Wuchter C., et al. Relaps in childhood acute lymphoblastic leukemia is associated with a decrease of the $\mathrm{Bax} / \mathrm{Bcl}-2$ ratio and loss of spontaneous caspase-3 processing in vivo. Leukemia. 14, 2000, 160613.

[14] Mulatsih S. Fusi gena TEL-AML1, BCR-ABL, E2A-PPBX1, dan MLL-AF4 sebagai faktor prognosis leukemia limfoblastik akut (Fakultas Kedokteran Universitas Gadjah Mada Yogyakarta. 2009).

[15] Biondi, Cazzaniaga, Masera. New stratification of childhood acute lymphoblastic leukemia. Hematology, 1, 2005, 133-7.

[16] Holleman A., Boer M.L., Kazemier M.R., Janka-Schaub G.E., Pieters R. Resistance to different classes of drugs is associated with impaired apoptosis in childhood acute lymphoblastic leukemia. Blood Journal Hematology, 102, 2003, 4541-4546.

[17] Faderl S., Thall P.F., Kantarjian H.M., Talpaz M., Haris D., Van Q., et al. Caspase-2 and Caspase-3 as predictors of complete remission and survival in adults with acute lymphoblastic leukemia. Clin Cancer Res.5, 1999, 4041-47.

[18] Meyer L.H., Karawajew L., Schrappe M., Ludwig W.D., Debatin K.M. and Stahnke K. Cytochrome c-related caspase-3 activation determines treatment response and relapse in childhood precursor B-cell ALL. Blood, 2008, 4524-31.

[19] Ghavami S., Hashemi M., Ande S.R., et al. 2009. Apoptosis and cancer: mutations within caspase Genes. J Med Genet., 46, 2009, 497-510.

[20] Lu Y.and Chen G.Q. Effector caspases and leukemia. Int J Cell Biology. 10, 2011, 1-8.

[21] Fulda S. 2009. Therapeutic opportunities for counteracting apoptosis resistance in childhood leukemia. British J Haematol. 145, 2009, 441-54.

[22] Miura M, Chen X.D., et al. 2004. A crucial role of caspase-3 in osteogenic differentiation of bone marrow stromal stem cells. Journal of Clinical Investigation. 114(12), 2004, 1704-1713.

[23] Darzynkiewicz Z.,Huang X., Okafuji M.,King M.,A. Cytometric methods to detect apoptosis. Methods cell biology, 75, 2004, 307341.

[24] Liu T., Raetz E., Moss P.J., Perkins S.L., Bruggers C.S., Smith F., Carroll W.L. Diversity of the apoptotic response to chemotheraphy in childhood leukemia. Leukemia. 16, 2002, $223-232$.

[25] alama M.A., Hassab H.M., Gendy W.E., Zeid M.Y. Study of caspase-3 level in relation to prognostic risk factors in children with acute lymphoblastic leukemia. Alexandria Journal of Pediatrics. 19(1), 2005, 45-49.

[26] Soung YH, Lee JW, Kim SY, Park WS, Nam SW, Lee JY, Yoo NJ, Lee SH. Somatic mutations of CASP3 gene in human cancers. Hum Genet., 115, 2004, 112-5.

[27] Shin S., Sung B.J., Cho Y.S., Kim H.J., Ha N.C.,Hwang J.I., et al. An anti-apoptotic protein human survivin is a direct inhibitor of caspase-3 and -7. Biochemistry, 40, 2001, 1117-23.

[28] Tamm I., Richter S., Oltersdorf D., Creutzig U., Harbott J., Scholz F., et al. High expression levels of x-linked inhibitor of apoptosis protein and survivin correlate with poor overall survival in childhood de novo acute myeloid leukemia. Clin Cancer Res.10, 2004, $3737-44$. 
[29] Vogler M., Giagkousiklidis S., Genze F., Gschwend J.E., Debatin K.M., Fulda S. Inhibition of clonogenic tumor growth: a novel function of smac contributing to its antitumor activity. Oncogene. 24, 2005, 7190-202.

[30] Fortugno P., Wall N.R., Giodini A., O'Connor D.S., Plescia J, Padgett KM., et al. Survivin exists in immunochemically distinct subcellular pools and is involved in spindle microtubule function. J Cell Sci, 115, 2002, 575-585

[31] Park E., Eun J.G.,Hsieh Y.T.,Schaeffer P., Chae S., Klemm L., et al. Targeting survivin overcomes drug resistance in acute lymphoblastic leukemia. Blood, 118(8), 2011, 2191-2199.

[32] Zhou M., Gu L., Li F., Zhu Y., Woods W.G., Findley H.W. DNA damage induces a novel p53-survivin signaling pathway regulating cell cycle and apoptosis in acute lymphoblastic leukemia cells. J Pharmacol Exp Therapy, 303, 2002, 124-31.

[33] Troeger A., Siepermann M., Escherich G., Meisel R., Willers R., Gudowius S., et al. Survivin and its prognostic significance in pediatric acute B-cell precursor lymphoblastic leukemia. Hematologica, the hematology Journal, 92 (8), 2007, 1043.

[34] Yahya R.S., Fouda M.I., El Baz H.A., Mosa T.E., Maksoud M.D.A. Serum survivin and TP 53 gene expression in children with acute lymphoblastic leukemia. Iranian J Publ Health, 41(1), 2012, 37-44. 